of $85.2 \%$ (95.0\% CI $81.9 \%$ to $88.4 \%$ ) participants affirmed that they could move with a deformed leper to the market or church. $71.5 \%$ (95.0\% CI $67.5 \%$ to $75.5 \%)$ participants stated that they could offer a job to a deformed leper.

Conclusion The high proportion of positive attitudes among the participants and in different divisions is a positive indicator that the elimination of leprosy social stigma is progressing in the right direction

\section{SP5-21 ASSESSMENT OF THE SPATIAL CLUSTERS OF KNIFE VIOLENCE: A CROSS-SECTIONAL STUDY IN NORTHWESTERN IRAN, USING GIS AND GPS, DURING 2009-2010}

doi:10.1136/jech.2011.142976p.57

${ }^{1} \mathrm{G}$ Kolifarhood, ${ }^{*}{ }^{2,3} \mathrm{~S}$ Salarilak, ${ }^{4} \mathrm{~S}$ Dastgiri, ${ }^{1} \mathrm{~N}$ Khosravi, ${ }^{3} \mathrm{P}$ Mikaili, ${ }^{3} \mathrm{M}$ Maleki, ${ }^{3} Y$ Mohammadpour, ${ }^{3}$ A Yousefzade. 'Zanjan University of Medical Science, Zanjan, Iran; ${ }^{2}$ Islamic Azad University of Iran, Tabriz Branch, Medical Faculty, Tabriz, Iran; ${ }^{3}$ Urmia University of Medical Science, West Azerbaijan, Iran; ${ }^{4}$ Tabriz University of Medical Science, East Azerbaijan, Iran

Objective To determine of spatial distributions of knife violence in Urmia, Iran, from 20 March 2009 to 21 March 2010

Material and Methods In this cross-sectional study, we studied the data of 703 new knife-assault victims, who attended to Accident and Emergency departments of three general Hospitals of Urmia, capital of West Azerbaijan province, during a 1-year period. The "Average Nearest Neighbor" method was used to identify the statistically significant geographical clusters. $\chi^{2}$ test was used for statistical analysis.

Results Countryside areas and shopping centers had significantly the most extensive spatial clusters of knife violence $(p<0.001)$. In summer season, there was different pattern in the clusters of the knife assaults in parks and recreation centers at hours of 19:00 to 3:00, which these data were added to the clusters of the other seasons. Considering space-time and socio-demographic status, teenagers and young single males were commonly as the victims of knife assaults in mentioned areas $(p=0.04)$.

Conclusion There is sufficient evidence about existence of knife stabbing violence clusters in Urmia. Understanding that, which areas of city have the high rates of the crime occurrence, provides potentially a unique opportunity for regional planners and policy makers by GIS (Geographic Information System)/GPS (Global Positioning System).

\section{SP5-22 THE ASSESSMENT OF CONTRACEPTIVE METHODS FOLLOWING THE 2009 PADANG EARTHOUAKE}

doi:10.1136/jech.2011.142976p.58

D Djafri. ${ }^{*}$ Faculty of Medicine, Andalas University, Padang, West Sumatra, Indonesia

Introduction The earthquake that hit Padang West Sumatra, Indonesia on 30 September 2009, extremely devastating one, registering 7.6-magnitude on the Richter scale. The destruction of health infrastructure and the displacement of population following the earthquake have increased the need of support with regard to the reproductive healthcare services in all health facilities. On the other hand, it has been demonstrated that providing reproductive health services is pivotal and especially to improving family planning during the earthquake.

Methods A community health center-based study was conducted to assess and examine the methods of contraception used contraception used before and within 1 year after the 2009 Padang earthquake. In total, 550 married women aged $15-49$ years old participated.
Results The study found difference in the utilisation of contraceptive methods before and after the earthquake. Within 1 year of the earthquake, use of condom significantly increased after the earthquake and the percentage of participants who used injections and implants tended to decrease. When compared before and after the earthquake, availability, affordability and acceptability of services in access to family planning services showed significantly affected by the earthquake.

Conclusion The earthquake affected to access in the utilisation of contraceptive methods. Availability, affordability and acceptability of services in access to family planning services were important to improving family planning during the earthquake situation.

\section{SP5-23 IS KNOWLEDGE AND ATTITUDE CORRELATING WITH PRACTICES? A KAP STUDY ON DENGUE FEVER}

doi:10.1136/jech.2011.142976p.59

A J Abedi, ${ }^{*}$ Z Khan, A Ansari, A Amir. J.N. Medical College, AMU, Aligarh, India

Introduction Dengue/Dengue Hemorrhagic Fever (DHF) is an emergent disease in India. It is endemic in some parts of country and contributes annual outbreaks of dengue/DHF.

Methods A cross sectional study was conducted in Aligarh, India, in peri urban area from October to November 2010 to asses knowledge, attitude and preventive practices on dengue. Randomly 120 adults were recruited by using Cochran's formula. Standardised oral questionnaire was used to collect information on demographic and dengue related KAP after taking informed consent. Knowledge and practices were graded good, fair and poor using Bloom's cut-off point and attitude was classified as positive, neutral and negative using Likert's scale. Reliability of questionnaire was analysed by using Cronbach's $\alpha$ Coefficient. The data collected was analysed by software SPSS version 17.0.

Results $42 \%$ respondents had low knowledge, $44.2 \%$ had positive attitude and $10.2 \%$ respondents followed good practices. Significant positive correlation was found between knowledge and practice $(\mathrm{p}<0.05)$, but no significance was found between attitude with knowledge or practice.

Conclusion The results suggested that good attitude does not translates into good practices, therefore health promotion activities should be strengthened for improving knowledge, ensuring people are receptive to the messages and making it easier for them to adopt desired change of behaviour.

\section{SP5-24 FAMILY, SCHOOL AND SOCIAL LIFE OF PUBLIC ASSISTANCE RECIPIENTS WITH ILLNESS/DISABILITIES IN KAGOSHIMA, JAPAN}

doi:10.1136/jech.2011.142976p.60

${ }^{1} \mathrm{C}$ Koriyama, ${ }^{*} \mathrm{~N}$ Yoshida, ${ }^{1} \mathrm{~S}$ Akiba. ${ }^{1}$ Kagoshima University Graduate School of Medical and Dental Sciences, Kagoshima, Japan; ${ }^{2}$ Division of Health and Welfare, Kagoshima Prefecture, Kagoshima, Japan

Backgrounds According to the 2008 report by Ministry of Health, Labour, and Welfare, the number of households receiving public assistance was nearly 1.2 million, and elderly households accounted for $46 \%$ of them, followed by households headed by individuals with illness/disabilities (36\%).

Aim The present study investigated family, school, and social life of public assistance recipients because of their illness/disabilities in Kagoshima, Japan, to identify predictive characteristics of high-risk group of public assistance recipients and to seek preventive measures against welfare dependence. 